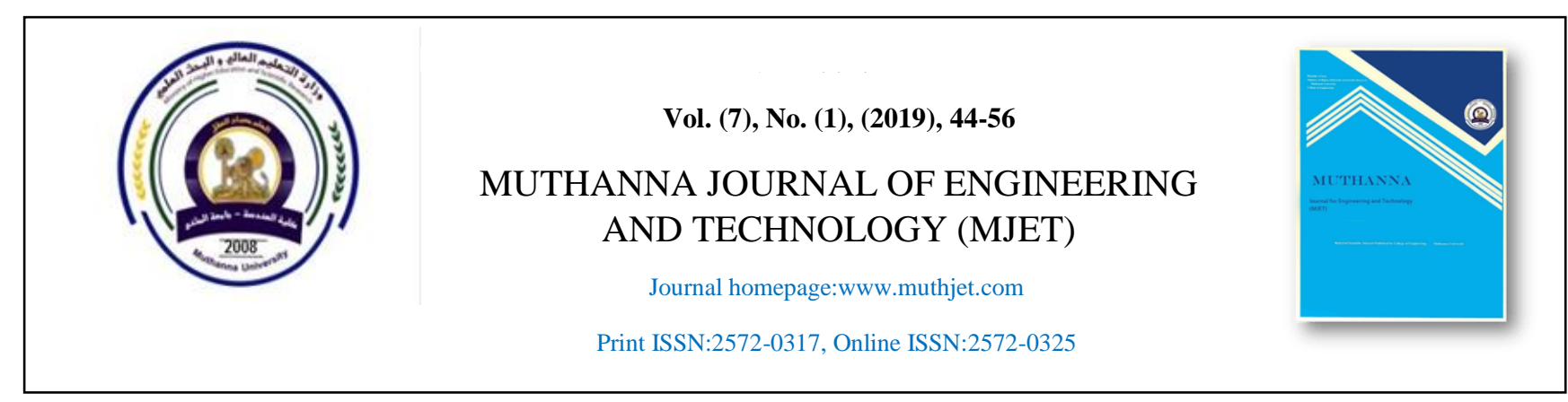

\title{
Architecture between Islamic thought and the phenomenon of deconstruct
}

\author{
Abdullah Saadoon Salman \\ Department of Architecture, University of Technology Baghdad
}

ARTICLE INFO

Received: 15-07-2019

Accepted: 08-09-2019

\section{Keywords}

Islam, thought of deconstruct, architecture thought.

\begin{abstract}
What inspires the learner or scholar in the field of architecture, as a need to satisfy, is the ability of the architect to deal with many of the architectural trends at the same time through the identification and investment in the creation of architectural configurations acceptable or have the balance among many architects. This approach has united the idea that architecture originated from a single source connected to man and his continuous quest to create an acceptable and acceptable environment. What interested the research is dealing with the Islamization of deconstruct architecture.

The research found the emerged from the architecture of deconstruct has achieved disjointed products of interpretation has been struck with the intention of the concept of unification in the architecture of Islam by abolishing the social concept and the impact of this in the creation of a unified architecture. While dealing with the texts shown in the Quran has achieved deconstruct as a purification of information by dealing with the phenomenon of production, it maintains its composition and do not deal with the deconstructive vision common to them. Or the circumference of the phenomenon as manipulated by the deconstruction through a distortion of the apparent configurations.
\end{abstract}

\footnotetext{
*Corresponding author:

E-mail addresses: absallah.asadoon@yahoo.com C2019 AL-Muthanna University. All rights reserved. DOI: $10.52113 / 3 / \mathrm{mjet} / 2019-7-1 / 44-56$
} 


\section{Introduction:}

Architecture can be defined in the relationship between mass and void and by the factors determined by Vitruvius in the first century AD: beauty, convenience and durability. (Vitruvius, 1960). Form is the result of mass and space. As for the architecture from the point of view of Islam, it is related to the divine dimension that affects the Muslim man in relation to the material of building architecture, which is different from the rest of the buildings. While man realized architecture as being the shelter of external circumstances. Art may be the material expression of a religious idea in man. Then the need arose and the development then began according to human needs. Over the ages, architecture has addressed these needs (challenges) and its outcomes have been different products that have fluctuated between good and bad, the more complex its needs, the more complex the job is, and the more innovative forms that contribute to satisfying these needs. The self is represented in the individual's desire to satisfy his or her inherent abilities and to realize himself in the same capacities, which are embodied in the longing for knowledge, learning and the desire to feel beauty in and of it.

\section{Research Problematic:}

The architect of the architecture raises the problem of dealing with the architecture of deconstruct because of its influences that dominate the architecture and entice it in productions that come out of the framework of tradition to frameworks that allow it to practice creative, self-sufficiency, to produce projects wrapped in philosophies and theories towards the world of fantasy away from the ground. One of the main concerns of the research problematic. structure of deconstruct architecture from the perspective of Islamic thought. The problem was identified in reading the architecture of deconstruct from the perspective of Islamic thought.

aims to:

Research Objectives: The research

- Highlight the role and effectiveness of Islamic thought, ideas related to Islamic architecture and the different periods of emergence of production.

- Identify the phenomenon of dismantlement architecture and their relationship with Islam - Understanding the architecture of deconstruct, and its relationship to the architecture of peace and Islam deconstruct.

\section{Research Methodology:}

The research uses the analytical method, which analyzes the data and variables of the research problem, and the accompanying variables that affect the resulting architecture using the models of Islamic architecture and the world.

The boundaries of the elements of research deal with the thought of Islam and its reflection on the architecture of deconstruct and attempt to demonstrate the effect of disintegration thinking on the Islamization of architecture, as illustrated in figure (1)

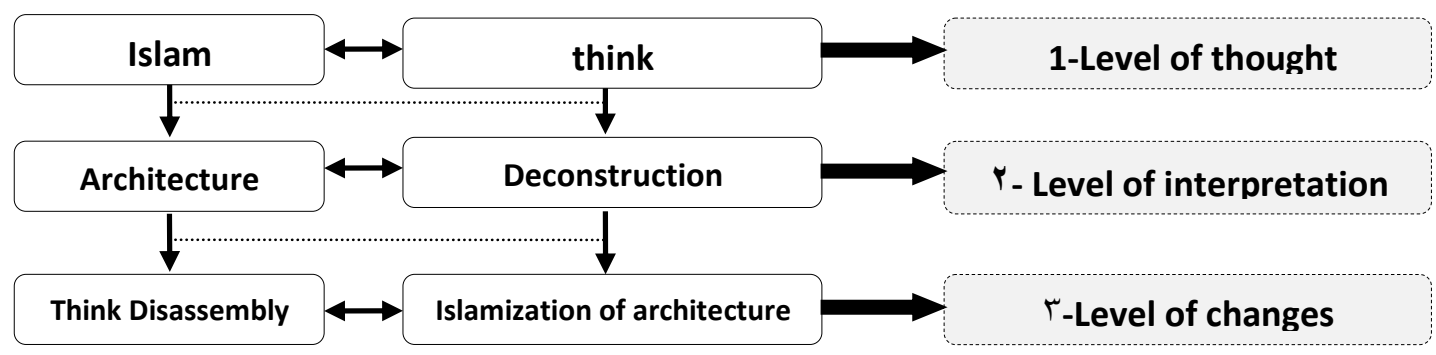

Figure 1: Problematic variables of research 


\section{Thought and Islam,}

Islam is one of safety, and the thought of Islam is a set of subjects that address the human mind in terms of reality and push it into reflection, observation and observation, and this process of thinking crystallizes into units in the form of questions in mind or problems that are exposed to humans, and the answer is with mental conviction and self-confidence. It is the natural birth of what is going on in the soul of feelings, thoughts and feelings.

While achieving the ability and effectiveness of Islam in keeping up with the age and its results and provide Islam and its achievements with a contemporary vision away from the approach of selectivity. That is linked to the concept of thought is the recognition, awareness, responsibility, freedom, and the intensity of feeling, thought, and imagination.

The thought carrying processes and mental forms performed by the human mind. While the process of thinking with information and contribute to the process of problem-solving and decision-making. Thought is related to man after thinking to choose a direction based on his approach to life and consistent with the human values that walk on it, and those intellectual trends and Marxist thought. Therefore, this vision works to reshape the mind capable of carrying out its mission and to exercise its intellectual and cultural role in the creations and achievements that take place within the framework of human ability. Which are at three levels?

The level of thought, human endeavor or the production of cognitive knowledge, as some of the students of architecture and architectural schools in the governance of Islam and the requirements of the age of social issues.

The level of interpretation of the product, through the response to the requirements of the age and the adoption of a set of standards and conditions and guidelines that control the movement of thought and the direction of the mind to produce the thought achieved goals and purposes.

The level of real and renewable changes through their developments, transformations and changes, through building the human and social aspects of knowledge according to the cognitive and educational style and finding the means of promotion that constitute personality. The university professor will then move away from the practical aspects, which constitutes a clear imbalance in dealing with these aspects

It is to achieve the proper handling of mind two levels: firstly, the dismantling of the world of ideas through the purification and his re-read the cultural balance and evaluation in light of the elements of production creative in time and space and dimension of civilization; and secondly, in building layout knowledge and cultural Islamic (al-Alwani, 1994, p. 49). The need to produce knowledge accumulations has emerged in the form of Islamic architecture.

Islam is the religion of all, and that recognizes your heart and recognizes Muslims from your tongue and your hand, and this is not complete Islam Abdul even loves the Muslims and left the abuse of his tongue, and left the abuse of his hand is not Islam Abdul and faith to occupy his tongue and his hand in the work in which it is useful to him The world and the Hereafter, , if this was achieved to become a safe Muslim in his home (the smaller society) and outside his home (the larger community) Good for what Allah loves and His Messenger. Thus, his architecture is a Muslim building with an internal environment in which the Muslim speaks in his tongue, and an external environment in which the Muslim handles 
his hand, which is the one that recognizes man from its external and internal influences.

The reasons for the difference between the periods of emergence of the product vary, and each successive period of inheritance has some causes. And that the most important reasons for the difference between today's architects and those interested in two levels in:

The level of ignorance of architecture and the acceptance of the ignorant, where it gets a similar situation in the equality of the products, which are similar as the flag of the apparent architecture.

And the level of incomplete science of architecture, where similar products come to the arbitrator, which does not get a change associated with the basic principles of architecture as the world of the hidden product of architecture. It is two-way

The first trend: the designer, that what is affected by the thought is the designer, may not see the designer with a few experience of architecture forms, and something of the meaning obtained either from the illusion is the wrong architecture, or the facts of things, and events in it, but it does not occur at all meaning Its associated form is not achieved at any time, either it is located and honest but it has multiple formations and each has its own pioneers, time and place located in it and shows the architects of multi-level architecture by the specialist.

The second trend: the product, includes the similarity in the products, the meaning and the events achieved and achieved over time, the same architectural form can mean multiple meanings. Each of these meanings applies to many configurations. The similarities are the best solution in dealing with society at different levels.

\section{As a result, Islamic architecture:}

The pioneers in dealing with many of the elements of architecture in the nontradition, but the search for methods of treatment and suitability to the Muslim community. The column, dome and arch may be from Greek and Roman capitals. Non-Arab elements. But then devised new ways to treat them .

(2), according to the nature of society, the values and traditions of that society, since Islamic architecture in India was formed (3). Different from the architecture in Turkey form (4) And the architecture of Persia. It defines the direction of Islamic architecture as an adaptive architecture and the fact that architectural elements are solutions and problems to the requirements that emerged in that period. Thus, architecture is the result of social requirements and environment in all its details.

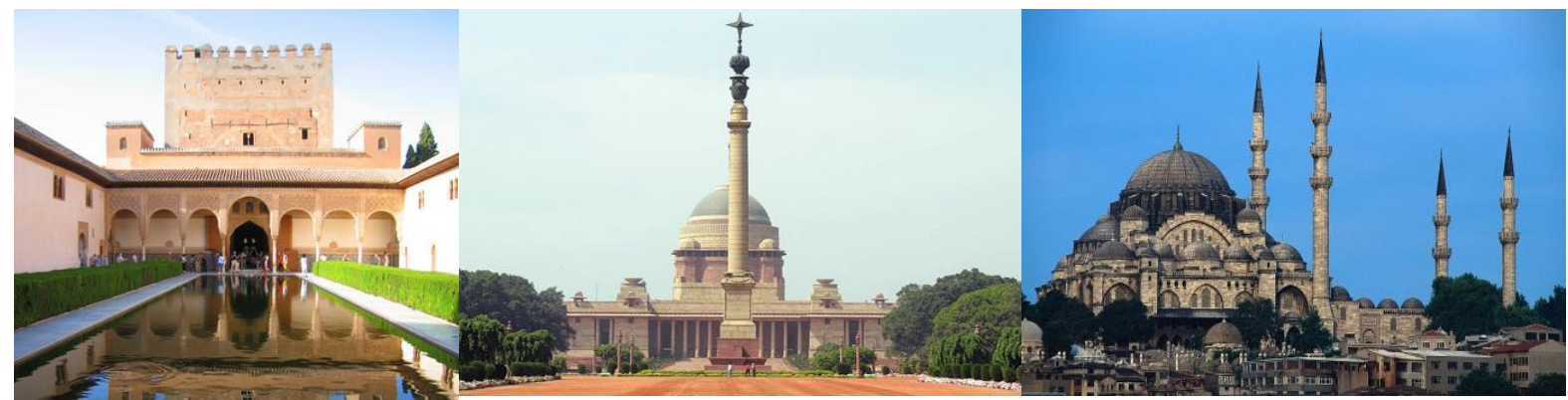

Figure (2) Al Hamra

Palace
Figure (3) Rashtrayati Bhawan founded by the British to establish the ruler of India
Figure(4) University of Sulaymaniyah This magnificent mosque is located on a hill 


\section{Deconstruct architecture:}

The architecture of deconstruction is one of the most influential trends in architecture. It represents a trend that tends to be more artistic than other architectural trends, as in the building of the museum at the entrance to Stuttgart in Germany, designed by UNStudio. The building represents a complete sculpture, it is characterized by abstraction and the use of modern materials and different angles within the same architectural work. A deconstruct is a position and has no author. Therefore, it is difficult to research the collection of the characteristics of deconstruct architecture as general characteristics, including the work methods of collecting the practicing architects to contrast the concepts, methods and vision of the deconstruct architecture to which they belong. The results of the pioneers were associated with ideas that characterized them and thus determined ideas associated with pioneer products.

\section{Discussion and Conclusions:}

The verification of solving the research problem was linked to the statement of the relationship between thought and architecture and three levels are the thought of deconstruct, the Islamization of architecture, the thought of architecture and the Islamization of deconstruct

\subsection{Deconstructing:}

Deconstruct is a distortion of a space organized rationally so that the elements within this space are forced into new relationships, characterized by cutting and fragmentation, not as a pattern or position, but as a method of questioning through and on techniques, social institutions and the establishment of metaphors of representation. Deconstructing architects embraced as a means of breaking down the concept of classical system and space. As well as moving away from the rules that restrict modernity in the purity of form and shape follows the function. The researchers pointed out that the arrangement of the lines forming the forms may take the lines of influence composition in general, distorting these lines and shows new trends as in the treatment of a model of decomposition in: formations, as in the project of fire extinguishing (1993).

5.2 From form and function to shape and content the deconstruct can be indicated in Figure 5: the dismantling of the content, when referred to by modernity in its vocabulary derived from Islamic architecture, I achieved her journey in:

- The perception of adopting the orientations of Islamic architecture, with their social content in the construction of formations acceptable form of social impact.

- Concept in achieving wider uses of the constants of Islamic architecture. And the credibility of the achievement of the fact that modernity and architecture is the savior and the unified and the doctor.

Thus, the changes were concerned with containing the meaning without form, and the form followed the function, which has been adopted by modernity since the beginning of thinking about the emergence of its products.

Disassembling the shape, when the technology showed its influence was helpful in the service of architecture, and achieved the forms requested by the architects. Multiple of The meaning in exchange for the survival of the form of the only influential in it. And verified the benefit of 
the controls of architecture formality in the production of architecture accepted by the
Arab community as the acceptance of forms of Islamic

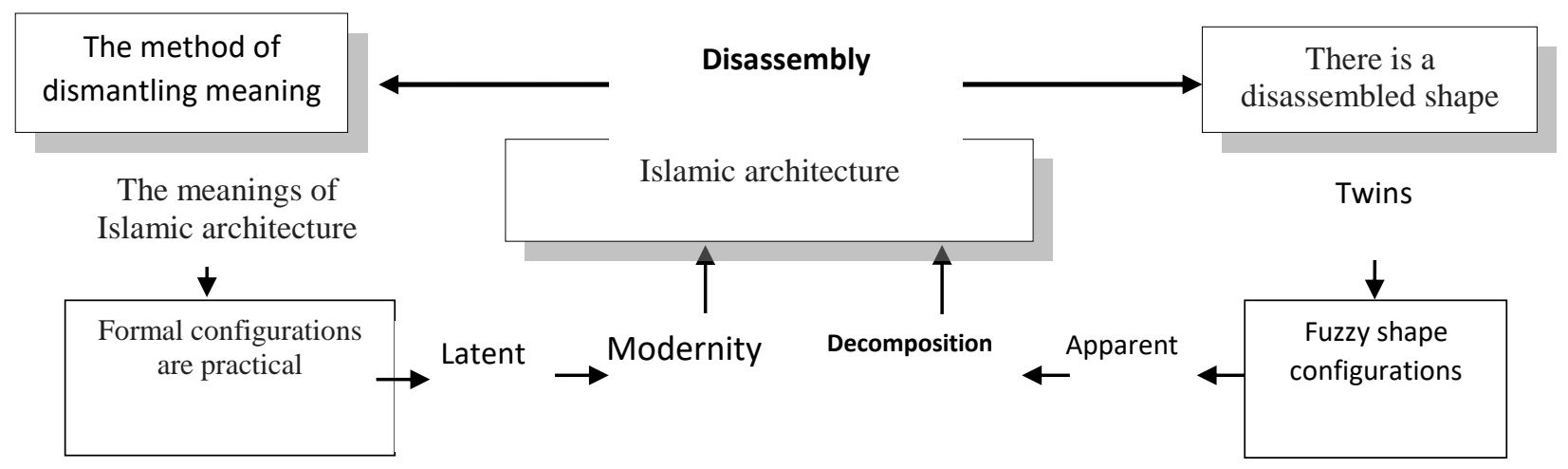

Figure (5) deconstruction in architecture

\subsection{Islamization of Architecture:}

Knowledge of what was dropped by Islam ideas has achieved an architecture characterized by efficiency and excellence, where architecture is known as antiquity. Islamic architecture adopted the understanding of substance and substance, not appearance. Here, the Arab Islamic architectural ability is manifested in the representation of architectural thought and its historical and cultural significance, which are linked to the nation's culture and its cultural output.

The Islamization of architecture has been linked to the theoretical aspect of the architectural formation of Islam, or to the knowledge of Islamic architecture, The Islamic Architecture adopted the understanding of the content and essence, not in appearance very firm judgment thought, Hence the ability of the thought of Muslim architecture in the representation of architectural thought of the civilizations they contacted in proportion to the Arab environment in terms of content and form. architecture.

As the concept of content is fundamental in Islamic architecture and as an expression of the functional and ideological aspects of the Muslim on the basis of the references drawn by the religion by its basic sources. The content is considered to represent a fixed expression that does not change with time and place, and is reflected with the aspects of the architectural form we see (the variable) which takes different forms according to the methods of implementation and building materials.

. The approach of the Muslim architect was to link the mind to a material state in geometrical geometry, and to understand the imagination and the sense of the designer, to produce a visual body to absorb them, and contribute to linking ideas with the engineering and sports assets of beauty and homogeneity. Thus, thought, engineering and mathematics are placed at the heart of Islamic architecture. whereas:

- The duty of the designer in his knowledge of himself and his presence, help him in arranging the material elements in the design by following the laws of engineering on the fundamentals of mathematical theories to form the design patterns, in line with the spirit of the age and the essence of understanding the importance of coexistence and dealing under the banner of Islam. As opposed to the state of coexistence to the various configurations in the dismantling 
architecture, as in the Center for Modern Art

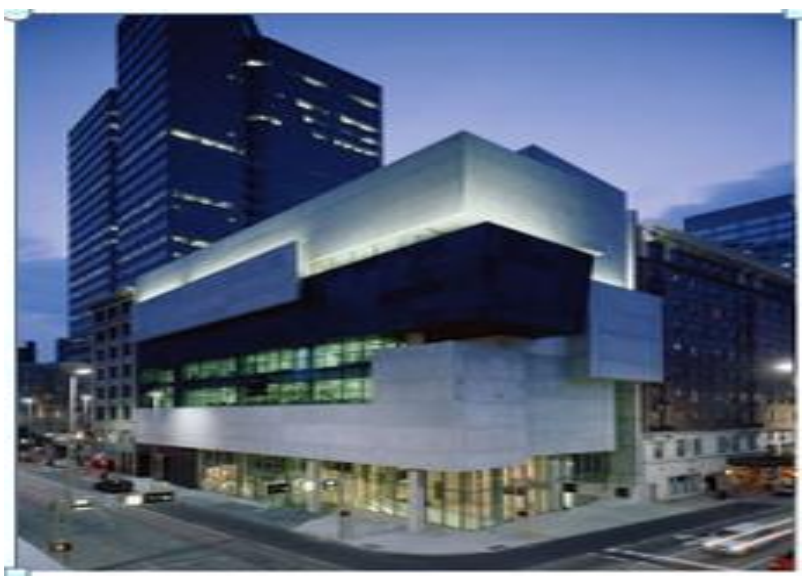

Figure (6) center for contemporary arts,

- The duty of the designer to know his creator, helping him to consider most of the provisions in the products subject to change, being the creation of time and place and social and cultural conditions in a specific society. This means that the provisions of Shari'a and jurisprudence are subject to change, and most of them are considered to be the creation of time and place in Islamic society. While the inertia is to move away from the spirit of eternal universal message of the Islamic religion (Melcan, 2010, p. 49). That is, to have an interest in the rationality of design ideas (being legal provisions) and their approximation of human rights and universal ethics which contemporary man understands and understands, , Figure (7).

- Getting the designer to know himself and the Creator, requires the call of other knowledge, which are answers to questions about dealing with knowledge of a different relationship in the difference of organization and distribution in the formation of the engineering panel with a specific way, in dealing and coexistence.

The Designer - access to knowledge itself or its creator, requires recall further knowledge, which answers to the questions about dealing with knowledge concerning the relationship of the different reactions in of Zaha Hadid, Figure (7).

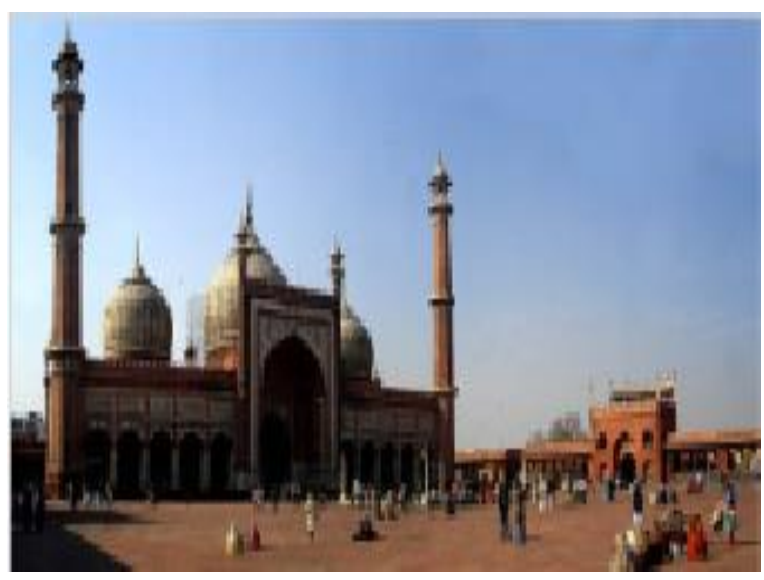

Figure (7) Mosque in Old Delhi

different organization and distribution in the formation of specific engineering board with how, in dealing and coexistence of the inhabitants of the product within the spirit of Islam in different areas of posts, and in a manner that is not contradictory engineering privacy with each other. When the attention of the Islamic architecture of the city, the social need for Muslims, Show Architectural Buildings that direct model to meet the social function with the culture to meet the characteristics of systems. Which the Islam content one, toward the Muslim cohesion with the surroundings and the feeling of belonging to the built environment, through human instinct designed to pay the discovery of relations between perceived things.

It helps the designer of the knowledge of the shaping of knowledge are Muslims, and then form the perceptions are the rules of knowledge models explain the foyer which deal with rights in the proximity and then its ability in the discovery of the relations of the Organization's life through his vision of the universe, man and life Halik each. Therefore, the knowledge base in neutral in the perception of the relations governing the rights through the senses as tools of knowledge and awareness. And architecture is one of the concepts of human knowledge from that building the knowledge 
base, we must distinguish between the forms of architecture of Islam, and her being different from the other building, this difference comes from the principle and its concept of life and man and the situation would be the phenomenon in different cultures, and the benefit and investment very diversified landscapes. There have been affected by the thoughts of the Islamic religion and Architecture, With Intellectual Unity associated with the CONSTANTS of the ideological and intellectual Islamic architecture has given clarity and consistency, making it features. The Forms resulting from Science and Industry (Technology), they may resemble the forms of universality, because they are the result of certain particular civilization or culture.
The architecture may be constructive through the health of all to know the health of the part, had been shattered all the parts of the honest and practical phenomenon in parts reaction

The curved blocks and overlapping may be adopted by Jerry in a unique configuration with signature ergonomically designed, it drops these forms clearly in all buildings of the configuration is like a fish, thus bold techniques. The curved blocks and overlapping may be adopted by Jerry in a unique configuration with signature ergonomically designed, it drops these forms clearly in all buildings of the configuration is like a fish, thus bold techniques.

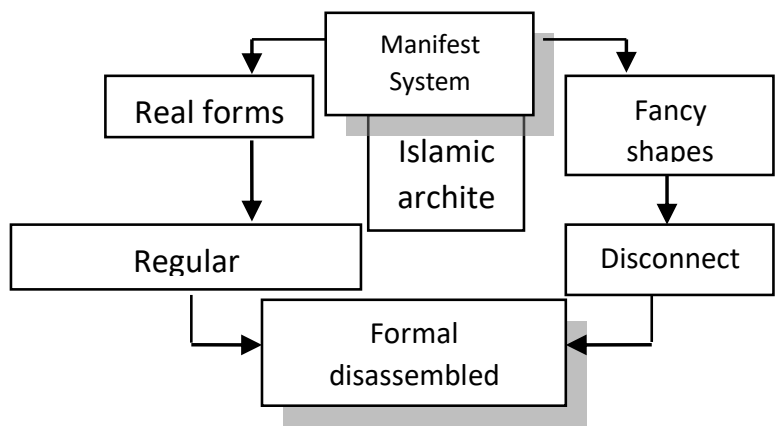

\subsubsection{The thought of architecture and the Islamization of deconstruct:}

And that what has been reported today's architecture of the stands queries, became the task of the human architect to meet the needs of his brother to provide certain services. He began to look at the ideas of man to build multiple but partial knowledge, May coincide with the emergence of a similar theory sprouted in conditions favorable to it, and similar to the cultural and intellectual stage of the previous philosophy. For this reason, it is not correct to search for an Islamic root, or the western root for the architecture of disintegration, of the philosophy of the architecture of Islam.

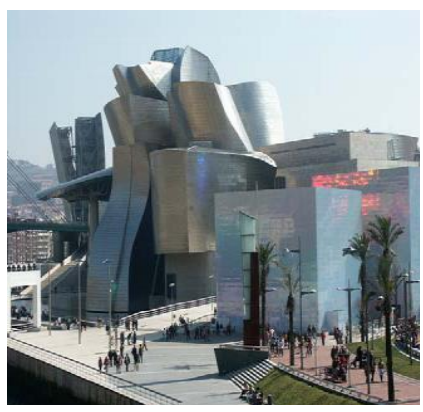

Even if they are similar or contradictory, yet this does not mean the abolition of the role of cultural communication between nations. Rather, we mean not to sacrifice the principle of originality and independence in the philosophy of Muslim architecture in favor of communication and citation in the architecture of deconstruct, or interaction between different schools of thought where:

First: Islamization of deconstruct:

Achieving the achievement of interesting formations Islamic through texts

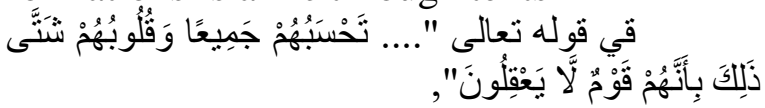

In this reference to the people of falsehood different testimony, different desires, different their work, and they are 
gathered in the hostility of the people of unanimous in their words, but their hearts are different to antagonize each other, The understanding of deconstruct as a difference in martyrdom, animosity, and business gives Islam the constitutive state and the exploitation of its self-meanings in the harmony and difference and its attributes towards a society that is realized in a Muslim architecture that unites ideas and orientations. It is clear that the Islam of deconstruct through the understanding of all in the definition of texts from the recipient is a disjointed architecture associated with its user, as reflected in the projects from the internal spaces to the outer spaces infinitely, the background of an Islamic architecture. And meets with the harmony and continuity between the internal and external spaces of Islamic architecture. The state of convergence between the Arabic calligraphy, its flow and the situation above, which means that the architectural imagination is affected. Including the Museum of Islamic Art in Doha and designed by the architect IMP, the design of the museum influenced the old Islamic architecture

The museum was inspired by its design of the "Wastewater Fountain" which was built during the thirteenth century at the Ibn Tulun Mosque in Cairo figure (9), dating back to the ninth century AD. Figure (10).

Second: deconstructionist Philosopher adopted on the structure of the truth. They think they are difference,(the presumptive thought):

Which is much more is difference, rather than the structure of the virtual similarity between the vocabulary next to dealing with the effects of the output to open the door to dialogue and misinterpretation by the recipient, Where it relates to the cognitive skill of the architect of the architecture, on the one hand, and the search for the state of congruence as a case in the description of the description of ideas and the treatment of parts of the product on the other hand, That is, what the architecture of deconstruct went from to taking the difference method as a strategy to read the work is achieved by changing the stable and the fixed to the unstable and not the fixed and this gave the field to interpret the receiver, The creation of complex architecture, through the dismantling of architecture traditions and re-installed in multiple configurations to produce a texture referred to by analogy as in the Tokyo Opera House project of architecture Nchome, has used the characteristics of intellectual forms. that is, architecture takes balance, displacement and distortion after what was a rational approach in modern architecture. Or the China Opera House of Zaha Hadid, iron drew this amazing form of gravel on the banks of the river, and its flowing exterior design inspired the effect of wind and water on the rocks to look like the building was carved. Figure (11)

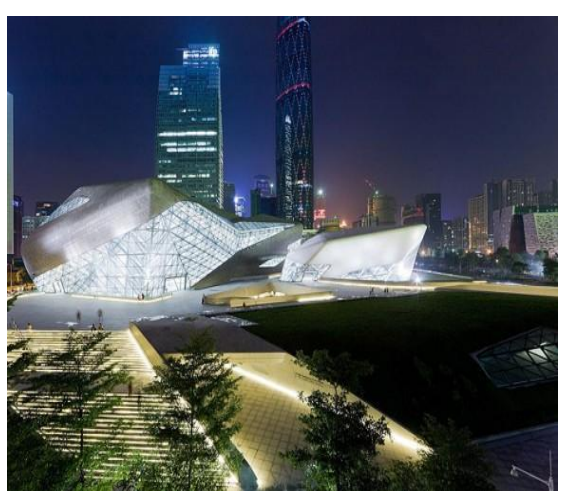

Figure (11) Opera House in Guangzhou / China, Zaha Hadid

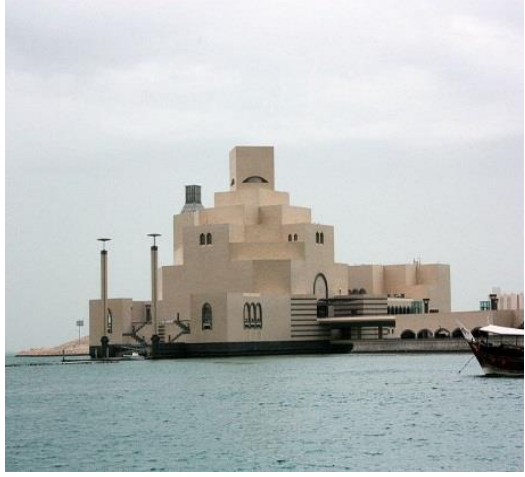

Figure (10) Museum of Islamic Art in Doha or

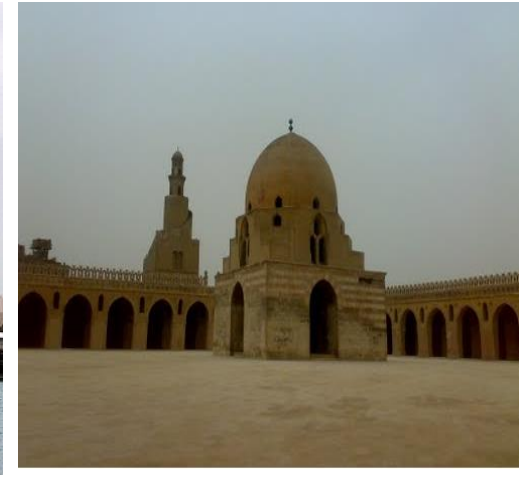

Figure (9) Mosque of Ahmed bin Toulon 
The mutation brought about by the deconstruction is similar to what every radical change in concepts that man considers to be a fact of truth requires a certain role to correct thoughts

The perception of the changing concepts of modern science confirmed the absence of an absolute reality and a fixed position and the lack of absolute dependence on the mind and its presence and the emergence of concepts such as suspicion, suspicion, and not inevitable deterministic probability and imprecision to show that the idea of deconstruction by Jacques Dareeda is the result Natural or SOA translation for all these variables

The deconstruct is misleading of direct significance but rich in significant intellectual property it denotes destruction and destruction, which are associated with the physical and visual forms,

Through Derrida's philosophy and thought in language and literature, he demonstrates the dismantling and revision of rhetoric and intellectual systems. While dealing with the instigation of the form and shake it up and blow up the main axis on which the emergence of metaphysical centrality of mind, Bearing in mind that philosophies are based on reason and word. Decentralization has therefore gone beyond the limits of ambiguity and multiple readings of the text.

Third: Ignoring the endless dismantling:-

(For text structure), without controls or limits. And the interpretation thereof to the extent possible if it is in accordance with the law and reference according to the ideological framework of the thought. Thus, the presence and absence of infinity is according to an Islamic vision and not according to the absurdity of the uncontrolled human mind.

- The deconstruction architecture achieved results emerged at the top of the far side of the architecture of Islam, Islam is achieved in the system of latent to a picture looking for contradictory if it is achieved in Islam is acceptable, If it refuses, it creates a disjointed architecture. As in this reference use belongs to the art and there are references that belong to nature

- Denial of the idea of place and internal containment and this displacement will transfer the place of production of the meaning of the architect to the reciver reader to explain and explain each according to the way of vision and background, as each architect achieved this displacement according to his vision and in a special way. For example chome, use of the fragmentation method was adopted. In the analysis to reach the new architectural system, where it separates form / function (construction / meaning), the form does not succeed function but tries to find a new concept dissolves both in one

- Much of the work referred to the philosophy of deconstruct, as a source of inspiration for this kind of challenge to tradition and expectation. Especially to the cooperation between Derrida and Peter Eisenman. There was an invitation from the architect to work with him on part of La Villette Park in Paris (Hale, 2000, p.77-78), To search for the pleasure of architecture that is not produced by the absence of rules, but from violation, violation and violation. The project represents a translation of Derrida's ideas, placing a question mark in front of the concept of public parks in today's city; It ignores the basic axioms of composition such as hierarchy, order 
and harmony. He created a public park without a coherent meaning, but every man sees him and explain in his own way. Chome has dismantled the architectural program. The grid is usually used to give the center and floor of the building a safe foundation, creating a building that is oblique, unpredictable and unpredictabl

\section{Fourth: Islamic Formations}

The formations and their
architecture were derived from the
intellectual aspects of the Islamic religion.
This was reflected in the cultural and
cultural aspects. Architecture was not
imposed on man, but it stems from the core
of his life. His idea is also to build sequential
growth with the needs of man and society
and the sense of belonging, In addition to
what Islamic art has given, in the service of
life as an applied art that participates in all
aspects of life, decorates the houses with a
wonderful Islamic architecture and uses it in
various aspects of life through a single
feature that characterizes the products of
Islamic civilization in any country of the
Islamic world

The other purpose of the research is one of the two homogeneous, interdependent concepts that are governed by interdependence so that they cannot be separated from each other. This is a part or a part of any formality or intellectual relationship, and in order to find the relations of integration and enrichment in them, the presence of one of them always requires the presence of the other.

This has made modernity of the other secondary and subordinate to him, that is, there is a determination in the clarity of the other and the appointment, came its results are one-meaning clear and explicit and reduced and free of any ambiguity, (Venturi) emphasized that the approach of modern architecture is based mainly on the principle of excluding the other through the use of the letter of kindness (or) within the custom of "either or that" (Venturi, 1987, p. 52), noting that the traditional rules adopted in all ideas of architecture Modern was focused on showing and highlighting or to praise the role of a party of bilateralism and to emphasize the meaning and neglect or marginalization of the other party's role (Gandelsonas, 1980, p.250) in dealing with the letter of sympathy (or) within the custom of "either or that" (Venturi, 1987, p. 52). Taking into consideration the clash of cultures and ideologies coming from outside the Islamic countries with the identity of the nation and its heritage and history, as a result of cultural and religious differences and conflicts (Birth, 2012, p. 84). Achieving a specific goal of thought is in the practice of achieving privacy, and this makes it intellectually incompatible with others, and materially in the vocabulary of its product. We need to:-

1. The Islamic thought based on the understanding of the spirit of Islam, its goals and rules, and the rules of its provisions through its two great sources: Quran and the rule of Prophet Mohammad

2. Studying the products of the pioneers of Muslim architecture

3. Research methods to understand Quran and the rule of Prophet Mohammad.

So that we can re-introduce Islamic perceptions and solutions to the suffering of our industry so that it is sure that Islam is the only way to save them and the best solution for all of their problems

What emerged from the architecture of deconstruct has achieved the results of disjointed interpretation, where it struck the concept of monotheism in the architecture of Islam through the abolition of the social concept and the impact of the creation of a unified architecture. The 
architecture of deconstruct has achieved the relationship between the diodes, It was defined through the concept of monotheism in the other architecture, the black known as white and life known as death ... and the realization of the revival of architecture linked to the construction of a Muslim life.The dealing with the texts shown in the Quran may achieve deconstruct by dealing with:

- phenomenon of the thing it maintains its composition and do not deal with the deconstruction (as an objective aspect)

- The circumference of the phenomenon: which is manipulated by deconstruction through distortion in its configurations

- The manipulation of the composition created a definition of the other party was the combination of them, but he asked to close one of them at the expense of the other to give the meaning of that in the understanding of the other.

That the research came from the information has been associated with the meanings of architecture, the whole fruit comes back to one name and one source was so named is what appeared by the output, and the upstream and the presence of architecture. 


\section{References:}

1. Afifi Dr.Mohammed Al-sadiq 1976

Islamic Thought .Al-khanchi

Library Cairo Al-Alwani

2. Taha Jabir .1994 Reform Islamic thought .International institute for Islamoc thought .International house for Islamic book $.2^{\text {nd }}$ Floor

3. Royal Decrees, Mustafa, 2010," the rationality and moral, the approaches in the philosophy of the Configuration. Translated by Dr. Abdul Jabbar Al Refai, Haidar Najaf, Publishers Arab sciences studies center, the philosophy of religion

4. VENTURI, Robert, 1987, "The complexity and contradiction in architecture," Translated by Soad Abd, review of dr. Ehsan Fathi, cultural affairs general assembly, Baghdad

5. Al-melad, Zaki, 2012, "The Islamic Thought, readings and reviews Arab Network research and publishing) Beirut, Lebanon, 1st Edition

6. Aln of the Working Group on", Journal of engineering and technological, Vol. 30, No.8.

7. Al Jabri, Mohammad Abid, 1980, "We and heritage, contemporary readings in the philosophical heritage", Dar Al-teleaa vanguard publishing, Beirut, 1980
8. Al- Yousef, Dr. Ibrahim Jawad, 2012, "Building the Architectural knowledge at architecture designed," 12Th International,

9. Al-Azhar Engineering Con- Yousef, Dr. Ibrahim Jawad, 2012, "an act of synchronization in the construction of the compositio ference Volume 7, No. 6, January

10. Hale, Jonathan A, 2000,'Building Ideas, an introduction to Architectural Theory', John Wiley\&Sons, LTD.

11. Vitruvius.1960. the Ten Books on Architecture (translated by M.H. Morgan), Ist edition. Dover Publications, Inc., New York.

12. Deconstructivism - California State University San Marcos, 1994,"Deconstruction and Graphic Design: History Meets Theory". Typotheque. public.csusm.edu/padil035/historypaper.htm

13. Wigley, Mark; 1989," Deconstructivist Architecture: Deconstruction " London; OMNIBUS VOL.; Academy Edilions.

14. Johnsen, Philip; 1988, "Deconstructivsts Architecture'; N.Y.; The Museum of Modern Art. 